\title{
PENGARUH MOTIVASI DAN KEPEMIMPINAN TERHADAP KEPUASAN KERJA KARYAWAN PADA AGENSI PEMASARAN PRODUK CABANG SURABAYA
}

\author{
Eko Purwanto', Sentot Imam Wahjono ${ }^{2}$, Dahruji ${ }^{3}$ \\ Universitas Muhammadiyah Surabaya \\ epurwanto1989@gmail.com ${ }^{1}$,wahjonos@gmail.com², Dahruji@yahoo.co.id ${ }^{3}$
}

\begin{abstract}
Human resources are important assets for the organization, a competent human resource can help the company in achieving its vision and mission. Therefore the company needs to pay attention to employee job satisfaction. The purpose of the study was to determine the effect of motivation and leadership on employee job satisfaction in product marketing agencies. The type of research method used was descriptive quantitative that focuses on testing hypotheses and is based on data obtained from questionnaires. The population at the agency was 30 employees. This study used saturated sampling (all populations become the object of research) of 30 respondents. There are three testing hypotheses in this study, 1. Motivation has a positive and significant effect on job satisfaction, 2. Leadership has a positive and significant effect on employee job satisfaction, 3. Motivation and leadership have positive and significant effects simultaneously on employee job satisfaction. Motivation theory used in this study was the theory of David McClelland. The leadership theory used in this study is the Continum theory (Tannenbaum and Schimidt).This research showed that the motivation and leadership were very important in influencing employee job satisfaction, it was expected that a manager could motivate her/his employees and delegate their duties effectively.
\end{abstract}

Keywords : Motivation, Leadership, Employee Job Satisfaction.

\begin{abstract}
Abstrak
Sumber daya manusia merupakan aset penting bagi organisasi. Sumber daya manusia yang berkompeten dapat membantu perusahaan dalam mencapai visi dan misi. Maka dari itu perusahaan perlu memperhatikan tentang kepuasan kerja karyawa. Tujuan penelitian ini adalah untuk mengetahui pengaruh motivasi dan kepemimpinan terhadap kepuasan kerja karyawan pada agensi pemasaran produk. Pendekatan penelitian ini adalah kuantitatif deskriptif yang menitikberatkan pada pengujian hipotesis dan didasarkan pada data-data yang diperoleh dari penyebaran kuesioner. Populasi pada agensi ini sebanyak 30 karyawan. Penelitian ini menggunakan sampling jenuh. Terdapat tiga hipotesis yang akan diuji dalam penelitian ini, 1. Motivasi berpengaruh positif dan signifikan terhadap kepuasan kerja kerja, 2. Kepemimpinan berpengaruh positif dan signifikan terhadap kepuasan kerja karyawan, 3. Motivasi dan kepemimpinan berpengaruh positif dan signifikan secara simultan terhadap kepuasan kerja karyawan. Teori motivasi yang dipakai dalam penelitian ini adalah teori David McClelland. Teori kepemimpinan yang dipakai dalam penelitian ini adalah teori Continum (Tanumbaum dan Scimith). Temuan penelitian ini menunjukkan bahwa motivasi dan kepemimpinan itu sangat penting dalam mempengaruhi kepuasan kerja karyawan, diharapkan seorang manajer dapat memberi motivasi kepada karyawannya dan dapat mendelegasikan tugasnya secara efektif.
\end{abstract}

Kata kunci : Motivasi, Kepemimpinan, Kepuasan Kerja Karyawan. 


\section{Pendahuluan}

Sumber daya manusia merupakan aset penting bagi organisasi dan menjadi prioritas utama, karena sumber daya manusia sebagai penggerak utama jalannya organisasi. Organisasi tidak akan dapat optimal kinerjanya apabila tidak memiliki karyawan yang kompeten, punya keahlian, dan berdedikasi tinggi terhadap keinginan organisasi. Di dalam persaingan global saat ini, dunia kerja sangat membutuhkan orang yang bisa berfikir untuk maju, cerdas, inovatif dan mampu bersaing dalam menghadapi kemajuan zaman. Pengelolaan sumber daya manusia yang dimaksud adalah bahwa perusahaan harus mampu menyatukan persepsi atau cara pandang karyawan dan pimpinan perusahaan dalam rangka mencapai tujuan perusahaan antara lain melalui pembentukan mental bekerja dengan baik dengan dedikasi dan loyalitas yang tinggi terhadap pekerjaanya, dengan memberikan motivasi, bimbingan, pengarahan dan koordinasi yang baik dalam bekerja oleh seorang pemimpin kepada bawahannya.

Menurut Wahjono, dkk. (2018: 87), menyatakan bahwa motivasi merupakan proses psikologi dasar. Banyak pakar perilaku organisasi percaya bahwa motivasi merupakan fokus terpenting dalam pendekatan mikro dalam perilaku organisasi. Selain motivasi, masih ada satu elemen yang bernilai penting dalam sistem manajemen perusahaan yaitu kepemimpinan (leadership).

Kepemimpinan adalah suatu proses dimana seseorang dapat menjadi pemimpin (leader) melalui aktivitas yang terus menerus sehingga dapat memepengaruhi yang dipimpin (followers) dalam rangka untuk mencapai tujuan organisasi atau perusahaan. Menurut Priansa (2017: 227) Mengemukakan bahwa kepuasan kerja identik dengan pegawai yang memiliki kompensasi kerja dan pengasilan kerja, akan tetapi semua yang di kemukakan benar, karena kepuasan kerja jauh melebihi kepentingan pegawai terhadap kompensasi dan penghasilan yang diperolehnya. Kepuasan kerja karyawan dengan karyawan yang lain itu berbeda, karena setiap karyawan memiliki tingkat kepentingan yang berbeda. Menciptakan kepuasan kerja karyawan adalah sangatlah tidak mudah karena kepuasan kerja akan tercipta jika variabel-variabel yang mempengaruhinya antara lain motivasi dan kepemimpinan (leadership) dapat diakomodasikan dengan baik dan dapat diterima semua karyawan disuatu organisasi perusahaan.

Perusahaan yang menjadi tempat penelitian adalah PT. Oze Mitra Nusantara (PowerSwitch) yang berlokasi di Sidoarjo. PT. Oze Mitra Nusantara adalah suatu agensi 
pemasaran yang menawarkan pemasaran across spektrum industri yang luas dengan fokus pada pengambilan sampel produk strategis, aktivasi merek, pemasaran pembelanjaan, mendapatkan wawasan lokal dan kecerdasan pemasaran. Sering kali karyawan tidak merasa puas akan hasil pekerjaan masing-masing dikarenakan sulitnya mencapai target kerja yang ditetapkan perusahaan dan banyaknya kendala saat dilapangan. Dari uraian tersebut peneliti ingin mengetahui apakah motivasi dan kepemimpinan berpengaruh terhadap kepuasan kerja. Karena itu peneliti mengambil judul "Pengaruh Motivasi Dan Kepemimpinan Terhadap Kepuasan Kerja Karyawan Pada Agensi Pemasaran Produk Cabang Surabaya”.

\section{Hipotesis Penelitian}

H1 : Motivasi berpengaruh positif signifikan terhadap kepuasan kerja karyawan pada agensi pemasaran produk.

H2 : Kepemimpinan berpengaruh positif signifikan terhadap kepuasan kerja karyawan pada agensi pemasaran produk.

H3 : Motivasi dan kepemimpinan berpengaruh positif signifikan secara simultan terhadap kepuasan kerja karyawan pada agensi pemasaran produk.

\section{Metode}

Sumber data menggunakan data primer dari karyawan PT. Oze Mitra Nusantara. Metode pengumpulan data dengan menggunakan kuisioner sebagai sarana mengumpulkan data. Teknik pengolahan data dalam penelitian ini dengan tabulasi. Fatihudin (2015: 138) menyatakan bahwa Tabulasi data yaitu mencatat atau data ke dalam table induk penelitian. Dalam penelitian ini tabulasi adalah kegiatan mengelompokan jawaban dari responden atas pernyataan dalam kuesioner yang disesuaikan dengan variabel kecerdasan emosional dan komitmen organisasi dan kinerja karyawan dan memasukkan ke dalam table supaya mudah dipahami.

\section{Pendekatan Penelitian}

Pendekatan penelitian yang digunakan dalam penelitian ini adalah pendekatan diskriptif kuantitatif. Pendekatan Kuantitatif merupakan suatu metode penelitian yang berlandaskan pada filsafat positivisme dan digunakan untuk meneliti pada populasi atau sampel tertentu, pengumpulan data menggunakan instrumen penelitian, analisis data bersifat kuantitatif/statistik, dengan tujuan untuk menguji hipotesis yang telah ditetapkan (Sugiyono, 2016: 8). 


\section{Teknik Analisis Data}

Metode analisis data yang digunakan dalam penelitian ini adalah analisis kuantitatif. Analisis dilakukan terhadap hasil dari kuesioner yang telah didapatkan selama proses penelitian. Proses analisis kuantitatif ini dilakukan menggunakan alat perhitungan statistik yaitu analisis regresi linear berganda dengan uji hipotesis yaitu uji t dan uji $\mathrm{F}$.

\section{Hasil dan Pembahasan}

\section{Analisis Regresi Berganda}

Tabel 1 Analisis Regresi Linear Berganda

\begin{tabular}{|c|c|c|c|c|c|c|}
\hline \multicolumn{7}{|c|}{ Coefficients $^{a}$} \\
\hline \multirow{2}{*}{\multicolumn{2}{|c|}{ Model }} & \multicolumn{2}{|c|}{ Unstandardized Coefficients } & \multirow{2}{*}{$\begin{array}{c}\begin{array}{c}\text { Standardized } \\
\text { Coefficients }\end{array} \\
\text { Beta } \\
\end{array}$} & \multirow[b]{2}{*}{$t$} & \multirow[b]{2}{*}{ Sig. } \\
\hline & & $\mathrm{B}$ & Std. Error & & & \\
\hline \multirow[t]{3}{*}{1} & (Constant) & 24.831 & 13.295 & & 1.868 & .073 \\
\hline & Motivasi & .462 & .189 & .399 & 2.442 & .021 \\
\hline & Kepemimpinan & .412 & .216 & .312 & 1.906 & .067 \\
\hline
\end{tabular}

Sumber : Hasil Olah SPSS v.22 (2020)

Berdasarkan tabel diatas, maka persamaan regresi yang terbentuk pada uji regresi ini adalah:

$$
\mathrm{Y}=24.831+0,399 \mathrm{X} 1+0,312 \mathrm{X} 2+\mathrm{e}
$$

Pada model diatas dapat diinterprestasikan sebagai berikut:

1. Konstanta (a) adalah sebesar 24.831 yang artinya jika variabel independen motivasi dan kepemimpinan bernilai konstan, maka variabel dependen kepuasan kerja karyawan nilainya sebesar 24.831 satuan.

2. Motivasi (X1) mempunyai nilai koefisien 0,399. Hal ini menunjukkan bahwa motivasi (X1) memiliki pengaruh positif terhadap kepuasan kerja karyawan (Y). Jika motivasi bertambah satu satuan, maka kepuasan kerja karyawan bertambah 0,399 satuan. Dapat diartikan semakin tinggi nilai motivasi maka kepuasan kerja karyawan semakin tinggi.

3. Kepemimpinan (X2) mempunyai nilai koefisien 0,312. Hal ini menunjukkan bahwa kepemimpinan (X2) memiliki pengaruh positif terhadap kepuasan kerja karyawan (Y). Jika kepemimpinan bertambah satu satuan, maka kepuasan kerja karyawan bertambah 
0,312. Dapat diartikan semakin tinggi nilai kepemimpinan maka kepuasan kerja karyawan semakin tinggi.

\section{Uji-t (Uji Parsial)}

Tabel 2 Hasil Uji-t (parsial)

\begin{tabular}{|c|c|c|c|c|c|c|}
\hline \multicolumn{7}{|c|}{ Coefficients $^{a}$} \\
\hline \multirow{2}{*}{\multicolumn{2}{|c|}{ Model }} & \multicolumn{2}{|c|}{ Unstandardized Coefficients } & \multirow{2}{*}{$\begin{array}{c}\begin{array}{c}\text { Standardized } \\
\text { Coefficients }\end{array} \\
\text { Beta }\end{array}$} & \multirow[b]{2}{*}{$t$} & \multirow[b]{2}{*}{ Sig. } \\
\hline & & $B$ & Std. Error & & & \\
\hline \multirow[t]{3}{*}{1} & (Constant) & 24.831 & 13.295 & & 1.868 & .073 \\
\hline & Motivasi & .462 & .189 & .399 & 2.442 & .021 \\
\hline & Kepemimpinan & .412 & .216 & .312 & 1.906 & .067 \\
\hline
\end{tabular}

Sumber: Hasil Olah SPSS v.22 (2020)

a. Uji t antara variabel motivasi (X1) terhadap variabel kepuasan kerja karyawan (Y)

Berdasarkan tabel diatas besarnya pengaruh motivasi terhadap kepuasan karyawan adalah 0,399 berarti terjadi pengaruh positif. Sementara uji signifikansi adalah 0,021 lebih kecil dari 0,05 maka temuan ini signifikan.

b. Uji t antara variabel kepemimpinan (X2) terhadap variabel kepuasan kerja karyawan (Y) Berdasarkan tabel diatas besarnya pengaruh kepemimpinan terhadap kepuasan karyawan adalah 0,312 berarti terjadi pengaruh positif. Sementara uji signifikansi adalah 0,067 lebih besar dari 0,05 maka temuan ini tidak signifikan.

\section{Uji F (Uji Simultan)}

Tabel 3 Hasil Uji-F (simultan)

\begin{tabular}{|c|c|c|c|c|c|c|}
\hline \multicolumn{7}{|c|}{ ANOVA $^{a}$} \\
\hline \multicolumn{2}{|c|}{ Model } & $\begin{array}{c}\text { Sum of } \\
\text { Squares }\end{array}$ & $\mathrm{df}$ & Mean Square & $\mathrm{F}$ & Sig. \\
\hline \multirow[t]{3}{*}{1} & Regression & 643.412 & 2 & 321.706 & 5.936 & $.007^{\mathrm{b}}$ \\
\hline & Residual & 1463.255 & 27 & 54.195 & & \\
\hline & Total & 2106.667 & 29 & & & \\
\hline \multicolumn{7}{|c|}{ a. Dependent Variable: Kepuasan Kerja } \\
\hline \multicolumn{7}{|c|}{ b. Predictors: (Constant), Kepemimpinan, Motivasi } \\
\hline
\end{tabular}

Sumber: Hasil Olah SPSS v.22 (2020)

Berdasarkan tabel diatas besarnya dapat dilihat bahwa nilai signifikansi $0,007<0,05$, maka dapat disimpulkan bahwa variabel independen (Motivasi (X1) dan Kepemimpinan (X2)) 
berpengaruh signifikan secara simultan terhadap variabel dependen yaitu kepuasan kerja karyawan (Y).

\section{Analisis Kofisien Determinasi (Uji $\mathbf{R}^{2}$ )}

Tabel 4 Analisis Koefisien Determinasi

\begin{tabular}{|c|c|c|c|c|}
\hline \multicolumn{5}{|c|}{ Model Summary } \\
\hline Model & $\mathrm{R}$ & R Square & $\begin{array}{c}\text { Adjusted R } \\
\text { Square }\end{array}$ & $\begin{array}{l}\text { Std. Error of } \\
\text { the Estimate }\end{array}$ \\
\hline 1 & $.553^{\mathrm{a}}$ & .305 & .254 & 7.362 \\
\hline
\end{tabular}

Sumber: Hasil Olah SPSS v.22 (2020)

Berdasarkan hasil pada tabel diatas dapat dilihat nilai koefisien determinan adalah 0,305, hal ini dapat diartikan variabel independen motivasi dan kepemimpinan mempunyai pengaruh terhadap kepuasan kerja karyawan sebesar 30,5\% atau sebesar 30,5 kepuasan kerja karyawan dapat dijelaskan oleh variabel motivasi dan kepemimpinan. Sedangkan sisanya sebesar 69,5\% dipengaruhi oleh variabel lain diluar penelitian ini seperti variabel insentif, komitmen dan lain sebagainya.

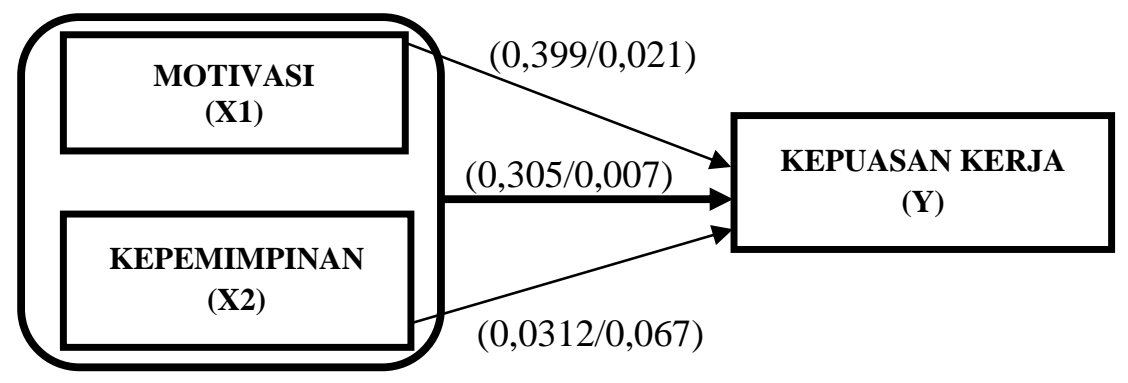

Gambar 1 Diagram jalur

Dari diagram diatas didapatkan hasil temuan sebagai berikut:

Tabel 5 Hasil Pengujian Hipotesis

\begin{tabular}{|c|c|c|c|}
\hline Hipotesis & Pengaruh & Sig. & Temuan \\
\hline H1 & Positif & Signifikan & Diterima \\
& $(0,399)$ & $(0,021<0,05)$ & \\
\hline H2 & Positif & Tidak Signifikan & Ditolak \\
& $(0,312)$ & $(0,067>0,05)$ & \\
\hline H3 & Positif & Signifikan & Diterima \\
& $(0,305)$ & $(0,007<0,05)$ & \\
\hline
\end{tabular}

Sumber: Hasil Olah Data SPSS v22 (2020)

Purwanto, Eko., Wahjono, Sentot I \& Dahruji. 2020. Pengaruh Motivasi dan Kepemimpinan Terhadap Kepuasan Kerja Karyawan Pada Agensi Pemasaran Produk Cabang Surabaya 


\section{Pembahasan}

Hasil perhitungan dan analisa program SPSS v22 dari data sampel sebesar 30 responden, menunjukan besarnya pengaruh motivasi sesuai teori David McClelland terhadap kepuasan karyawan adalah 0,399 berarti terjadi pengaruh positif. Sementara uji signifikansi adalah 0,021 lebih kecil dari 0,05 maka temuan ini signifikan. Jadi H1 diterima. Maka pada hipotesis pertama yang berbunyi "Motivasi berpengaruh positif dan signifikan terhadap kepuasan kerja pada Agensi Pemasaran Produk Pada Cabang Surabaya" adalah terbukti kebenarannya. Semua indikator tersebut sangatlah penting terhadap kepuasan kerja karyawan, karena setiap karyawan harus mempunyai keinginan untuk mencapai sesuatu tujuan yang ingin dicapainya dan berani menyampaikan saran kepada pimpinan apabila itu sangatlah penting. Selain itu karyawan juga butuh inputan atau masukan dari teman kerja sebagai bahan pertimbangan untuk pengambilan keputusan.

Temuan ini selaras dengan penelitian Makrodi dan Komarudin (2017) yang hasilnya motivasi berpengaruh terhadap kepuasan kerja karyawan di PT. Asuransi Jiwa Mega Life. Hal ini ditunjukkan dengan nilai $t_{\text {hitung }}$ lebih besar dari $t_{\text {tabel }}(11,139>1,16531)$. Pada penelitian ini untuk motivasi kerja karyawan khususnya dalam hal berprestasi dikatakan cukup tinggi. Oleh karena itu perlu adanya peningkatan penghargaan yang antara lain menambah pemberian insentif dengan memperhatikan aturan-aturan yang berlaku, perjalan dinas baik dalam maupun luar negeri. Hal ini bertujuan agar mereka lebih dihargai.

Hasil perhitungan dan analisa dari program SPSS v22. menunjukkan besarnya pengaruh kepemimpinan sesuai teori Continnum (Tanumbaum dan Smitch) terhadap kepuasan karyawan adalah 0,312 berarti terjadi pengaruh positif. Sementara uji signifikansi adalah 0,067 lebih besar dari 0,05 maka temuan ini tidak signifikan. Jadi $\mathrm{H} 2$ ditolak, maka pada hipotesis kedua yang berbunyi "Kepemimpinan berpengaruh positif dan signifikan terhadap kepuasan kerja pada Agensi Pemasaran Produk Pada Cabang Surabaya" adalah tidak terbukti kebenarannya. Dalam teori continuum menjelaskan bahwa sebelum memilih gaya kepemimpinan manajer harus memperhatikan ketiga kekuatan di atas. Tapi dari hasil yang di dapat karyawan masih ragu-ragu tentang gaya kepemimpinan di PT. Oze Mitra Nusantara. Hal ini menunjukkan bahwa manajer belum dapat memberikan kepuasan kerja terhadap karyawan. Karena peranan pemimpin itu sangatlah penting untuk karyawan dalam hal pekerjaan. Karyawan akan merasa puas apabila kepemimpinan yang diterapkan sangat efektif. 
Temuan ini tidak selaras dengan penelitian Makrodi dan Komarudin (2017) yang menjelaskan bahwa kepemimpinan berpengaruh terhadap kepuasan kerja karyawan di PT. Asuransi Jiwa Mega Life. Hal ini ditunjukkan dengan nilai thitung lebih besar dengan $t_{\text {tabel }}(7,462$ > 1,6531). Pada hasil penelitiannya kepemimpinan di PT. Asuransi Jiwa Mega Life sangatlah baik tapi perlu juga ada penyesuaian gaya kepemimpinan dalam situasi dan kondisi terhadap masalah penugasan maupun personal pegawai.

Hasil perhitungan dan analisa dari program SPSS v22. Menunjukkan bahwa Motivasi (X1) dan Kepemimpinan (X2) berpengaruh secara simultan dan signifikan terhadap kepuasan karyawan (Y). Hal ini diketahui dari hasil perhitungan SPSS yang ditunjukkan dengan nilai pengaruh motivasi dan kepemimpinan $(0,305)$ dan nilai signifikansinya 0,007 yaitu lebih kecil dari 0,05. Jadi pada hipotesis tiga yang berbunyi "motivasi dan kepemimpinan berpengaruh positif dan signifikan secara simultan terhadap kepuasan kerja karyawan pada Agensi Pemasaran Produk Cabang Surabaya" adalah terbukti kebenarannya. Jadi hipotesis ketiga diterima. Hal ini menunjukkan bahwa meskipun kepemimpinan tidak signifikan tapi jika dilakukan bersama-sama dengan motivasi yang signifikan maka hasilnya akan signifikan terhadap kepuasan kerja karyawan. Berarti perusahaan harus memperhatikan keinginan dalam hal terkait motivasi (teori McClelland) seperti pemberian insentif apabila mencapai target, memberi kesempatan karyawan untuk menyampaikan pendapatnya supaya lebih dianggap oleh perusahaan dan yang terakhir memberi kebebasan untuk berhubungan antar karyawan dan menjembataninya supaya tidak terjadi suatu hal yang tidak diinginkan. Meskipun demikian seorang manager harus memperbaiki sistem kepemimpinannya supaya lebih efektif sehingga jika terjadi masalah pada karyawan dapat di selesaikan secepatnya.

Temuan ini selaras dengan penelitian Makrodi dan Komarudin (2017) yang hasilnya motivasi dan kepemimpinan secara simultan berpengaruh terhadap kepuasan kerja karyawan di PT. Asuransi Jiwa Mega Life. Hal ini ditunjukkan dengan nilai $F_{\text {tabel }}(6,473>1,9693)$. Pada penelitian ini juga menyatakan bahwa variabel yang paling banyak mempengaruhi kepuasan kerja karyawan adalah variabel motivasi dengan nilai $t_{\text {hitung }}$ sebesar 11,139.

Berdasarkan perhitungan dan analisis koefisien deteminan dapat diketahui nilai koefisien determinan adalah 0,305, hal ini menunjukkan bahwa variabel motivasi dan kepemimpina mempunyai pengaruh terhadap kepuasan kerja karyawan sebesar 30,5\% sedangkan sisanya sebesar 69,5\% dipengaruhi oleh variabel lain seperti budaya organisasi, komitmen kerja, Purwanto, Eko., Wahjono, Sentot I \& Dahruji. 2020. Pengaruh Motivasi dan Kepemimpinan 8

Terhadap Kepuasan Kerja Karyawan Pada Agensi Pemasaran Produk Cabang Surabaya 
disiplin kerja dan lain sebagainya.

\section{Kesimpulan}

1. Sesuai teori David McClelland, motivasi berpengaruh positif dan signifikan terhadap kepuasan kerja karyawan pada agensi pemasaran produk cabang Surabaya. Hal ini ditunjukkan dengan nilai pengaruhnya sebesar 0,399 dan nilai signifikansinya sebesar 0,021 yaitu lebih kecil dari 0,05. Maka hipotesis pertama diterima.

2. Sesuai teori Continnum (Tanumbaum dan Smitch), kepemimpinan berpengaruh positif dan tidak signifikan terhadap kepuasan kerja karyawan pada agensi pemasaran produk cabang Surabaya. Hal ini ditunjukkan dengan nilai pengaruhnya sebesar 0,312 dan nilai signifikansinya sebesar 0,067 yaitu lebih besar dari 0,05. Maka hipotesis kedua ditolak.

3. Sesuai Makrodi dan Komarudin (2017), motivasi (teori David McClelland) dan kepemimpinan (teori Continnum) secara simultan berpengaruh positif dan signifikan terhadap kepuasan kerja karyawan pada agensi pemasaran produk cabang Surabaya. Hal ini ditunjukkan dengan nilai pengaruhnya sebesar 0,305 dan nilai signifikansinya sebesar 0,007 yaitu lebih kecil dari 0,05. Maka hipotesis ketiga diterima. Dari kedua variabel tersebut yang paling mempungaruhi kepuasan kerja adalah variabel motivasi, hal ini dapat dilihat dari nilai pengaruhnya yang paling besar yaitu 0,399.

\section{Saran}

Berdasarkan hasil dari penelitian dan pembahasan serta kesimpulan yang telah diuraikan, maka penulis mengemukakan beberapa saran yang dapat dijadikan masukan bagi PT. Oze Mitra Nusantara pada Cabang Surabaya. Adapun saran-saran sebagai berikut:

1. Perlu ada peningkatan pada penambahan dalam pemberian insentif keuangan berupa tambahan gaji dengan menetapkan aturan-aturan sesuai ketetapan perusahaan. Hal ini bertujuan supaya karyawan lebih semangat dalam bekerja dan dalam mengejar target yang sudah ditetapkan.

2. Perlu ada pembenahan dalam hal terkait kepemimpinan yang dilakukan oleh manajer seperti lebih mendisiplinkan karyawan untuk lebih mematuhi aturan perusahaan, mengatur distribusi barang sesuai dengan tingkat kepentingan dan kebutuhan. Hal ini bertujuan agar karyawan merasa puas terutama dalam mengatasi setiap permasalahan yang terjadi. 
3. Kepuasan kerja dapat muncul atau terjadi jika permasalahan yang terdapat dalam pelaksanaan motivasi kerja dapat diatasi dengan baik, dan kepemimpinan dapat menyesuaikan dengan situasi dan kondisi, sehingga dapat menentukan langkah-langkah perbaikan agar kepuasan kerja karyawan lebih meningkat. Motivasi kerja yang dilakukan dapat sesuai indikator yaitu need for achievement yaitu kebutuhan akan prestasi sehingga karyawan akan senantiasa bekerja untuk mencapai prestasi yang lebih baik. Kepemimpinan yang diterapkan dapat disesuaikan akan kekuatan dalam situasi yang artinya pimpinan harus lebih melihat situasi dan kondisi dalam melaksanakan pekerjaan.

\section{Daftar Rujukan}

Fatihudin, Didin. 2015. Metode Penelitian. Sidoarjo: Zifatama PUBLISHER

Ismail, Hasan \& Rahmawati, Rini. 2014. Pengaruh Gaya Kepemimpinan Dan Motivasi Kerja Terhadap Kepuasan Kerja Karyawan (Studi Pada Politeknik Tanah Laut Di Kabupaten Tanah Laut). Jurnal Wawasan Manajemen Vol. 2 No.1

Mukrodi dan Komarudin. 2017. Pengaruh Kepemimpinan dan Motivasi terhadap Kepuasan

Kerja Karyawan di PT Asuransi Jiwa Mega Life. Jurnal Ilmiah Prodi Manajemen Universitas Pamulang, 4(2),124-139.

Paramita, Lalujan., Lengkong, Victor P.K., Sendow, Greis M. 2016. Pengaruh Komunikasi Organisasi Dan Stres Kerja Terhadap Kepuasan Kerja Serta Dampaknya Terhadap Kinerja Karyawan Di Perusahaan Umum Bulog Divisi Regional Sulawesi Utara. Jurnal EMBA Vol.4 No.1

Parimita, Widya., Prayuda, Wendi Hadi., Handaru, Agung Wahyu. 2013. Pengaruh Lingkungan Kerja dan Budaya Organisasi Terhadap Kepuasan Kerja Karyawan Pada Bank BTN (Persero) Cabang Bekasi. Jurnal Riset Manajemen Sains Indonesia (JRMSI) Vol.4 No.2

Priansa, Donni Juni. 2017. Manajemen Kinerja Kepegawaian. Bandung: CV Pustaka Setia.

Profita, Dihan., Surachman, Andarwati. 2017. Pengaruh Kepemimpinan, Budaya Organisasi, Motivasi Terhadap Kepuasan Kerja dan Kinerja Karyawan Pada Dinas Pemerintahanan Desa Kabupaten Lumajang (Pemdes). Jurnal Bisnis dan Manajemen Vol.4 No.2

Sarita, Jena., Agustia, Dian. 2011. Pengaruh Gaya Kepemimpinan Situasional, Motivasi Kerja, Locus Of Control Terhadap Kepuasan Kerja Dan Prestasi Kerja Auditor. Jurnal Fakultas Ekonomi Universitas Airlangga

Sugiyono. 2016. Metode Penelitian Kuantitatif, Kualitatif, dan R\&D. Bandung: CV. Alfabeta. Wahjono, Sentot Imam. 2013. Pengaruh Keefektifan Kepemimpinan Terhadap Kepuasan Kerja Di Perusahaan Berbasis Keluarga. Journal of Business and Banking Vol.3 No.1 
Wahjono, Sentot Imam. Marina, Anna. Maro'ah, Siti dan Widayat. 2018. Pengantar Bisnis. Jakarta: Prenadamedia Group.

Rozzaid, Yusron., Herlambang, Toni., dan Devi, Anggun Meyrista. 2015. Pengaruh Kompensasi Dan Motivasi Terhadap Kepuasan Kerja Karyawan (Studi Kasus Pada PT. Nusapro Telemedia Persada Cabang Banyuwangi). Jurnal Manajemen Dan Bisnis Indonesia Vol. 1 No. 2 